\title{
ESTUDOS
}

\section{Carreira do magistério: uma escolha profissional deliberada?}

Ione Ribeiro Valle

\section{Resumo}

Analisa a dinâmica que determina a escolha da carreira docente, a partir de representações de um grupo de professores de $1^{\mathrm{a}}$ a $4^{\mathrm{a}}$ série, supondo que ela é impulsionada por razões que podem ser circunscritas histórica e geograficamente. Procura primeiramente compreender a lógica das escolhas profissionais, elucidar a noção de carreira e distinguir as motivações que influíram na decisão desses professores ou que os impelem a outras profissões, despertando velhos sonhos e nutrindo novas ambições. Para tanto, constrói um esquema de interpretação, destacando algumas lógicas que orientam o percurso escolar e influenciam os itinerários profissionais: a lógica de integração, relacionada com a imagem de si mesmos; a lógica de profissionalização, associada à sua inserção no mundo do trabalho; e a lógica de transformação, que faz referência à sua função social.

Palavras-chave: carreira do magistério; corpo docente; identidade profissional.

\section{Abstract}

The teaching career: is it a deliberated professional choice?

His study analyses the dynamic which determine the choice of the teaching career, beginning from a group of primary teachers, supposing it is stimulated by reasons that can be historical and geographically circumscribed. Firstly, we tried to understand the logic of these professional choices. We also tried to elucidate the concept of career and distinguish the motivations that had influenced in these teachers decisions, or that impelled them to other professions, awaking old dreams and feeding new ambitions. To understand this, we built a scheme of interpretation, highlighting some logics that guide the scholastic course and influence the professional journey: the integration logic related to self image: the professionalization associated to work market insertion; and the logic of transformation that makes reference to its social functions.

Keywords: teaching career; instructing staff; professional identity. 
O propósito de constituir uma carreira para o magistério integra os objetivos das esferas administrativas, estando associado à idéia de corpo unificado considerada indispensável à ampliação de sua eficiência e produtividade. $\mathrm{O}$ ingresso no magistério supõe um determinado grau de formação correspondente ao nível de ensino pleiteado e a aprovação em concurso, requisitos essenciais à construção de uma carreira profissional e à afirmação da identidade do professor. No entanto, a tardia e frágil democratização do sistema de educação brasileiro - quanto à sua expansão e à oferta de um ensino de qualidade acaba postergando a edificação dessa carreira e favorecendo uma enorme fragmentação do corpo docente. Respaldado no princípio de descentralização amplamente proclamado pelas políticas educacionais desde os anos 50, o sistema educacional apresenta-se estratificado em redes e níveis de ensino, fazendo com que o magistério acumule desigualdades profundas em termos de status, salário, contrato e condições de trabalho.

Mas a intenção de estabelecer uma carreira profissional faz parte principalmente das reivindicações dos professores, tendo sido explicitada com veemência por suas esferas representativas (associações e sindicatos), sobretudo a partir dos anos 80. Associada à idéia de profissionalização do sistema de ensino e do pessoal da educação - inspirada na concepção de modernidade - e ao desejo de engendrar uma "identidade profissional" inscrita numa outra realidade dinâmica e contingente, diferenciada da "identidade vocacional" ${ }^{1}$ difundida pelas Escolas Normais, a carreira é vista como fundamental ao engajamento dos professores nas lutas coletivas do magistério, o que somente a condição de membro integral do corpo docente parece ser capaz de promover.

Partindo da dinâmica - muitas vezes efêmera e ambígua - que orienta as escolhas profissionais, formulamos a hipótese segundo a qual a opção pelo magistério repousa sobre algumas lógicas, relacionadas com as representações que o professor tem de si mesmo, de sua inserção no mundo do trabalho e de sua função social. Com o objetivo de examinar esta hipótese, procuramos compreender a lógica das escolhas profissionais, elucidar a noção de carreira a partir de diferentes abordagens teóricas e distinguir as motivações que influíram na decisão de professores de $1^{\mathrm{a}}$ a $4^{\mathrm{a}}$ série ou que os impelem a outras profissões, despertando velhos sonhos e nutrindo novas ambições.

\section{Uma escolha circunscrita}

Ao contrário do que revela o senso comum, o destino de uma pessoa não se prende somente às características próprias de sua personalidade - disposição, inteligência, caráter, vocação, aptidão, dons e méritos pessoais, que podem ser cultivados de maneiras diversas -, mas depende principalmente do fato de ter nascido num determinado momento histórico e num certo ambiente sociocultural, definido por elementos estruturais bem precisos: de ordem econômica, política, educacional. Esses elementos pesam sobre as opções de cada um e acabam por prescrever o futuro no mais longo termo, orientando a escolha pessoal e exercendo forte influência sobre o itinerário profissional. O apelo à vocação para justificar as escolhas profissionais, como salientou Bourdieu (1998), visa produzir encontros harmoniosos entre as disposições e as posições, fazendo com que as vítimas da dominação simbólica possam desempenhar com satisfação as tarefas subalternas ou subordinadas, atribuídas às suas virtudes de submissão, gentileza, docilidade, devotamento e abnegação.

A idéia de deliberação voluntária, normalmente associada às qualidades inatas, supõe que toda decisão resulte da escolha entre múltiplas possibilidades, o que permite diversificar as estratégias, prognosticar suas conseqüências e avaliar comparativamente as vantagens e benefícios de cada uma delas. Todavia, como ressalta Bourdieu (1989), as escolhas profissionais não são simplesmente fruto de uma decisão consciente realizada por um sujeito racional, mas de uma operação, freqüentemente obscura, de um senso prático da posição no campo, orientada pela estrutura interiorizada que produziu toda a história anterior e que ainda conduz o presente.

Embora se desconheça a lógica das escolhas profissionais que se efetuam quase sempre fora de todo cálculo e sem critérios explicitamente definidos, consideramos que nelas são engajados princípios de seleção, esquemas de percepção e de apreciação que não são aleatórios. 
A escolha inicial e normalmente prematura de uma profissão - que na era moderna se torna cada vez menos definitiva, dependendo cada vez mais das flutuações do mercado e da extensa especialização das áreas profissionais - é apenas uma, dentre as muitas, que se sucedem na vida. Apesar disso, não podemos esquecer que essa escolha está relacionada com objetivos, nem sempre muito claros, que se quer perseguir, e com o grupo de referência no qual se pretende buscar prestígio, distinção, realização.

Desse modo, para se compreender as escolhas individuais, é fundamental levar em conta as estruturas objetivas do campo profissional, assim como suas lógicas de funcionamento e de transformação. Este estudo parte do pressuposto de que a escolha ocupacional deriva não somente da posição social dos pais, ligada, portanto, à atividade que exercem, mas está igualmente vinculada à sua posição sociocultural ou aos seus níveis de escolarização. Com base nesses parâmetros, a família delimita a escolarização dos filhos ou projeta a continuidade dos estudos, determinando assim as fronteiras de suas ambições profissionais. Circunscrita ao leque de possibilidades abertas pela família e decorrente de múltiplas articulações entre a vida familiar e a vida profissional, a escolha da carreira docente - que exige um longo tempo de preparação - depende muito estreitamente do capital escolar e cultural (nos termos formulados por Bourdieu) que o jovem estudante porta.

\section{Atualidade do termo}

Designando originalmente as vias destinadas às corridas, o termo "carreira" adquiriu duplo sentido figurado, referindose ao itinerário de uma pessoa no curso de sua vida ou de uma parte dela e à progressão a que cada indivíduo faz jus no interior das modernas organizações burocráticas. Podem existir numerosas carreiras durante uma vida, e muitas delas não são nem organizadas nem definidas de maneira consciente. Mas a palavra carreira é empregada principalmente como atributo das profissões que oferecem possibilidades de promoção, estando reservada apenas a algumas delas. Ainda que não estejam livres de imprevistos e de irregularidades, certas carreiras profissionais possuem um caráter mais duradouro e estável que outras e valem-se de status diferenciados.

A carreira está inscrita na era da burocracia, sublinha Hughes (1996): na condição de funcionário, uma pessoa pode galgar as camadas superiores de uma organização hierárquica, num período em que recebe um salário e lhe são conferidos graus distintos de autoridade e prestígio segundo o nível exercido. Todavia, a idéia de carreira não pode ser empregada apenas nesse sentido. Goffman (1968) atribui ao termo um duplo significado, que abrange questões íntimas mantidas preciosa e secretamente por cada um, como a imagem de si e o sentimento de sua própria identidade, e refere-se à situação oficial do indivíduo, às suas relações de escolha, ao seu modo de vida. O conceito de carreira integra assim o quadro das relações sociais, autorizando um movimento de vai-e-vem do público ao privado, do eu ao meio social, que dispensa o recurso abusivo das declarações do indivíduo sobre si ou sobre a idéia que faz de seu próprio personagem. Segundo Huberman (1989), o desenvolvimento de uma carreira é um processo e não uma série de eventos: para alguns esse processo é linear, para outros ocorre em etapas, com regressões, declínios ou descontinuidades. O conceito de carreira permite então estudar o percurso de uma pessoa numa organização (ou numa série de organizações) e compreender, ao mesmo tempo, a influência que essas pessoas exercem sobre a organização e as situações institucionais a que se submetem.

É na acepção moderna do termo que inscrevemos o estudo sobre a escolha da carreira docente, relembrando que, como membro do magistério, o professor integra um corpo profissional relativamente fechado - muito embora apareça mais fragmentado do que unificado - e se define por um tipo de identidade ${ }^{2}$ (vocacional ou profissional). Ao qualificar o sistema educacional como burocracia pedagógica, Lapassade (1989) mostra que sua estrutura hierárquica, a exemplo das demais organizações modernas, oculta uma teia complexa de relações de poder, que, no caso brasileiro, estão distribuídas em níveis e redes de ensino. Essas relações operam a partir de uma gama de trabalhos a efetuar, correspondendo a toda uma gama de papéis administrativos e pedagógicos a desempenhar. Ainda que a docência se

\footnotetext{
Segundo Dubar (2000), identidade não é o que permanece idêntico, mas o resultado de uma identificação contingente. É o resultado de uma dupla operação da linguagem: diferenciação e generalização. A primeira refere-se à singularidade de alguma coisa ou de alguém em relação a outra coisa ou a outrem: a identidade é a diferença. A segunda procura definir o ponto comum a uma classe de elementos, diferentes dos que compõem uma outra classe: a identidade é a vinculação comum.
} 
situe no interior desse sistema e se constitua a sua principal atividade, o magistério está submetido às decisões tomadas nas esferas superiores. Os professores podem até mesmo se beneficiar de aumentos salariais consideráveis, mas jamais se beneficiarão das gratificações supremas. Para tanto, é necessário remover-se da carreira docente para uma função na administração, na pesquisa ou nas altas esferas político-educacionais, diferentemente de outras profissões onde se pode chegar ao ápice sem abandonar a atividade de base.

A partir dessas abordagens, consideramos que a carreira docente se inscreve à primeira vista entre duas dinâmicas contraditórias, que evoluem em sentido inverso: ela figura entre as carreiras valorizadas socialmente, porque combina um certo status profissional com estabilidade de emprego (características até há pouco tempo exclusivas das profissões tradicionalmente reputadas como "nobres”), colocando os professores ao abrigo das grandes flutuações do mercado; ela pode também servir de lugar de passagem ou trampolim para algumas funções administrativas.

Mas a carreira docente se torna pouco atrativa, pois, apesar de exigir um enorme investimento pessoal e familiar (diplomas e aprovação em concursos), oferece um futuro profissional bastante incerto, baixos salários, limitadas possibilidades de ascensão pessoal, condições precárias de trabalho, além de requerer uma grande versatilidade; o exercício do magistério implica inevitavelmente a conciliação da atividade de ensinar e de outras que lhe são complementares, seja por sua natureza, seja em razão da organização do trabalho escolar. Essas dinâmicas convergem em favor de duas idéias fundamentais:

1) A escolha do magistério resulta de uma decisão consciente ou inconsciente tomada durante a escolarização média, ou até mesmo antes dela, em razão da atração que a carreira docente exerce sobre o jovem estudante. Este se investe, então, na realização de seu projeto profissional, colocando em prática múltiplas estratégias. Nesse caso, pode-se supor que os futuros professores não escolhem a docência com o objetivo de ascender a uma posição socialmente reconhecida haja vista a crise profunda que afeta o magistério -, mas acreditam poder conquistar essa posição e apostam na sua revalorização, contentando-se com uma solução provisória e com as perspectivas de uma promoção futura.

2) A escolha do magistério pode, por outro lado, ser provocada pela impossibilidade de concretizar um outro projeto profissional, seja devido a circunstâncias diversas de ordem pessoal - geralmente decorrentes de uma condição familiar homogênea e unívoca de existência -, seja pela oferta limitada de habilitações profissionais, em que predominam igualmente as estruturas objetivas dessa condição. ${ }^{3}$ Nesse caso, os sonhos e projetos do jovem estudante se confrontam com a lógica das hierarquias escolares, que, condicionadas pelas hierarquias sociais e culturais, são típicas das sociedades marcadas por fortes desigualdades. Sendo forçados a renunciar aos sonhos relativos às profissões que desejariam exercer, os futuros professores investem sua energia, talento e sabedoria na segunda - ou talvez terceira - escolha ligada àquela profissão que pensam realmente poder exercer; nela buscam realização pessoal e procuram vivê-la como a concretização plena de uma vocação. ${ }^{4}$

\section{Escolha da carreira docente}

O interesse principal pela escolha da carreira docente, estudada com base nas representações de um grupo de professores, ${ }^{5}$ inspira-se no esforço de Bourdieu (1979) em construir sua teoria do habitus procurando compreender de maneira unitária algumas dimensões da prática, analisadas freqüentemente em ordem dispersa. Mas, a exemplo do que faz Lahire (1998), não se pode insistir exclusivamente no aspecto "sistemático" e "unificador" do habitus - que, ao presumir a homogeneidade do passado, bloqueia prematuramente o encontro entre um passado incorporado e um presente diferente ou contraditório -, pois a articulação passado/presente (incorporado/contexto) só tem 
sentido se estes forem considerados ao mesmo tempo como plurais e heterogêneos. Isto significa considerar que o peso das experiências passadas na situação presente está relacionado com as aspirações do professor e as lógicas de ação nas quais ele foi e é conduzido a se inscrever.

Para compreender as motivações dos professores interrogados no que concerne à escolha da carreira docente, que ocorreu num passado distante ou recente, em virtude das diferenças de idade e do desejo de mudar de profissão, recorremos a dois conceitos: dom e vocação, que têm simultaneamente explicado o ingresso no magistério e justificado os projetos profissionais vislumbrados.

Considerando a multiplicidade de estudos nos campos sociológico e educacional sobre o dom, não podemos mais nos basear somente na noção clássica, que o confunde com as idéias de disposição inata e natural, de bênção ou de graça, e que o associa a abnegação e sacrifício. Nosso interesse consiste, portanto, em examinar em que medida as representações dos professores revelam a adesão pura e simples à ideologia do dom ou expressam a crença em seus dons individuais.

Referindo-se à "dupla verdade do dom”, Bourdieu (1997) ressalta que a doação, como ato generoso, só pode ser praticada por agentes sociais que adquiriram em universos preparados e reconhecidos as disposições generosas, ajustadas às estruturas de uma economia que lhes assegura algum tipo de recompensa, sob a forma de contradoação ou de distinção. Valorizando o ato de doar, oculta-se o fato de que tanto aquele que dá quanto aquele que recebe são preparados pelos mecanismos de socialização (primária e secundária) para participar da troca generosa, reconhecendo-a pelo que representa em si mesma.

Igualmente, não se pode mais recorrer à vocação no seu sentido moral e ético ou mesmo religioso ${ }^{6}$ como razão única das escolhas profissionais. Esses sentidos atribuem às profissões uma especificidade própria, sui generis, que exige um tipo de engajamento pessoal e familiar e constrói nos indivíduos o sentimento de uma predestinação marcada pelo espírito missionário.

Fruto da doação e da vocação, a escolha do magistério implica inevitavelmente ligações afetivas no nível da relação pedagógica (professor/aluno) e institucional (professor/ direção/colegas), mas decorre também das significações acordadas à própria profissão. Ora, estas ligações estão permeadas pela submissão e autoridade, dimensões associadas ao dom e à vocação, que se expressam na linguagem da obrigação: obrigado, ele obriga, faz obrigado, cria obrigações, institui uma dominação legítima (Bourdieu, 1997). Essa linguagem é eficaz para dissimular a violência simbólica e assegurar a perpetuação do poder de dominação das elites sobre a massa, dos dominantes sobre os dominados, dos herdeiros sobre os despossuídos (Bourdieu, 1989).

Dois fatores, o sexo e a origem social, influíram no ingresso dos professores na carreira docente, colocando-se na base de um paradoxo: ao orientar o jovem estudante para o reconhecimento de suas características pessoais - principalmente sexuais - e para a necessidade de adaptação às condições socioeconômicas reais, esses fatores acabam por desencorajar a escolha de uma outra habilitação profissional e considerar como legítima a ideologia da excelência escolar.

Atribuindo suas escolhas à vocação e aos seus dons pessoais, resultado da interiorização de um futuro profissional possível e provável, os professores de $1^{\mathrm{a}}$ a $4^{\mathrm{a}}$ série interrogados, ou, mais precisamente, as professoras ( $97 \%$ da amostra), fazem reviver certos estereótipos que autorizam e favorecem determinadas condutas e técnicas sociais, mas também sexuais ou evocadas sexualmente, além de permitir a consolidação e legitimação de atitudes diferenciadas. Esses estereótipos são geralmente inconscientes e constituem-se fatores de censura e de autocensura, que atuam na seleção das orientações: às mulheres o contato humano, a ajuda aos outros, a comunicação. Segundo Dubar e Tripier (1998), a divisão sexuada dos papéis familiares é inseparável das desigualdades de carreira profissional entre os sexos.

A origem social dos professores interrogados $^{7}$ é consideravelmente modesta: a grande maioria descende da população em transição entre as zonas rurais e os centros urbanos, provém das camadas sociais em ascensão passando das ocupações manuais às profissões intelectuais, faz parte dos setores menos escolarizados portadores de baixo capital cultural. Em conseqüência, a escolarização aparece como via - talvez única - de promoção social e

\footnotetext{
A vocação desempenha o papel da mutação na seleção natural, permitindo às pessoas que a encontram dar um sentido à sua existência, saber por que despendem energia, ter em mente que realização que atingem é, melhor do que a fortuna, a prova de sua predestinação (Tripier, 1998).

7 A variável origem social foi elaborada a partir do nível de escolaridade e do tipo de ocupação dos pais.
} 
lhes permite romper com a hereditariedade profissional, ingressando nas atividades mais bem qualificadas, entre as quais figura o magistério.

A fim de examinar as motivações que impulsionaram esses professores para o magistério e que os atraem para outras profissões, construímos um esquema de interpretação sociológica, na tentativa de buscar uma maior objetividade no tratamento das informações. Esse esquema coloca em destaque algumas lógicas que orientam o percurso escolar e influenciam os itinerários profissionais desses professores, a saber: a lógica de integração, relacionada mais diretamente com a imagem de si mesmos; a lógica de profissionalização, associada principalmente a sua inserção no mundo do trabalho; a lógica de transformação, que faz referência à sua função social. Essas lógicas não são autônomas, mas formam verdadeiros "canais de interdependência” (Elias, 1970) que se diferenciam e se distanciam, tornando-se quase imperceptíveis e escapando do controle do próprio indivíduo e de seu grupo de vinculação.

\section{A lógica de integração}

Muitos estudos constataram que a escolha de uma profissão é o resultado de uma combinação entre a representação que o indivíduo tem de si e a experiência vivida. Para Bourdieu (1997), as escolhas do sujeito livre e desinteressado que exalta a tradição não são totalmente independentes da mecânica do campo, da posição que nele ocupa e dos interesses que lhe são solidários; portanto, da história da qual ele é o resultado e que permanece inscrita nas suas estruturas objetivas e, através delas, nas estruturas cognitivas, nos princípios de visão e de divisão, nos conceitos, nas teorias, nos métodos utilizados.

A escolha da carreira docente parece ser proveniente do esforço contínuo de integração em um determinado universo social ou profissional relativamente constante, como é o caso do magistério. Esse esforço é cuidadosamente engendrado no seio da família (socialização primária), onde são nutridas as motivações intrínsecas, incorporadas através de orientações coerentes e fortemente homogêneas. Estas visam adaptar as singularidades e expectativas pessoais e delimitar as ambições profissionais, procurando enquadrar em cada bifurcação (passagem de um nível de ensino a outro) as escolhas individuais.

A consolidação progressiva da lógica de integração se prolonga pela vida adulta, sendo efetivada através de estratégias implícitas e/ou explícitas, meticulosamente implementadas por programas duráveis de inculcação (socialização secundária), onde se cruzam princípios heterogêneos ou mesmo contraditórios.

Pudemos constatar assim que as motivações para o ingresso no magistério, evocadas pelos professores interrogados, permanecem no campo dos valores altruístas e da realização pessoal, estando fortemente ancoradas na imagem de si e na experiência cotidiana, a saber: o dom e a vocação ("tenho características inatas indispensáveis ao ensino”), o amor pelas crianças ("adoro trabalhar com as crianças”), o amor pelo outro ("eu sempre gostei de ajudar as pessoas”), o amor pela profissão ("adoro o trabalho escolar", "formando os outros, a gente se forma a si mesmo"), o amor pelo saber ("é uma profissão que possibilita minha realização pessoal”), a necessidade de conquistar autonomia financeira ("o fato de entrar no magistério me permite ganhar a vida e continuar os estudos"). ${ }^{8}$

As razões pessoais, mesmo sendo muito complexas e difíceis de ser apreendidas, baseiam-se nas afinidades individuais alimentadas desde a mais tenra idade ("eu sou dotada para o ensino", "desde criança sonhei tornar-me professora”, “eu adorava fazer o papel de professora”), nas lembranças de práticas vividas no círculo familiar ("eu sempre fui atraída pela profissão de minha mãe, ela era professora”, "eu admirava minha tia professora”), nas relações com o meio escolar ou em impressões ancoradas na escolaridade ("minha primeira professora me inspirou muito", "sempre tive bons professores”), mas também no acaso onde agem o destino e as situações inesperadas ou inusitadas ("quando me dei conta, já era professora”).

Tentando aprofundar esta reflexão, procuramos analisar as expectativas dos professores diante da possibilidade de exercer uma outra profissão. Verificamos, então, que mais de dois terços se diziam satisfeitos e não pretendiam abandonar a docência. Em contrapartida, um terço está pronto a deixar o magistério se a ocasião 
se apresentar e sustenta, inclusive, a idéia de "colocar o ponteiro a zero" em termos de futuro profissional. Esses professores acumulam frustrações pessoais diante das "promessas" não concretizadas e demonstram um sentimento profundo de desilusão ("não consigo desenvolver minhas potencialidades nesta profissão”), que decorre tanto da falta de valorização financeira e reconhecimento social ("os baixos salários se tornaram insuportáveis”, “o ensino torna-se cada vez mais desvalorizado”) quanto dos limites impostos pela própria profissão ("tenho vontade de conhecer coisas diferentes”, "gostaria de descobrir o mundo”).

\section{A lógica da profissionalização}

A lógica de integração é reforçada e ampliada no interior de um universo profissional relativamente homogêneo, onde são criadas e recriadas as idéias fundamentais que definem as condições de formação de seus componentes, que são também as condições de sua realização pessoal. A estima de si aparece como um dos elementos da identidade profissional, devendo ser construída e modificada de maneira mais ou menos consciente por cada um ao longo de sua trajetória. Escolher a docência é, portanto, atribuir-lhe um sentido, situando-a em relação à sua vida e às suas aspirações profissionais; é inserir-se num espaço social bem preciso e num sistema de relações interpessoais claramente definidas, com o objetivo de reafirmar a estima de si.

Atribuindo suas razões ao desejo, mas sobretudo à necessidade de inserir-se no mercado de trabalho, os professores interrogados se viram atraídos pelo "amor à profissão" e pelo “amor ao saber” no momento de ingressar no magistério, que para a maioria deles foi seu primeiro emprego. Em geral, isto aconteceu muito prematuramente (entre 13 e 20 anos), mas não restringiu suas ambições pessoais; eles foram - ou continuam sendo - forçados a conciliar a vida de estudante com a vida profissional.

O que mais motivou esses professores foram algumas características da profissão: horários flexíveis, liberdade de ação, o fato de ser uma profissão "adequada e desejável” às mulheres, a estabilidade e as perspectivas que proporciona ("é um mercado em expansão”), as facilidades de acesso (baixas exigências de nível de formação) e, principalmente, seu prestígio em relação às ocupações manuais ("o ensino ainda é valorizado”, "os salários continuam atraentes se compararmos com outras profissões”).

Os professores que desejam exercer outra profissão ressaltam as dificuldades de ascender na carreira docente ("não se pode mais esperar nada desta profissão”) e o esgotamento próprio do trabalho escolar ("o ensino tornou-se insuportável por causa das más condições das escolas, dos baixos salários e dos freqüentes problemas com os alunos”). Suas preferências concernem às atividades administrativas, mas principalmente técnicas, científicas e artísticas (bioquímica, agronomia, medicina, odontologia, veterinária, fisioterapia, enfermagem, informática, psicologia, assistência social, advocacia e jornalismo).

A continuidade dos estudos também faz parte dos projetos de um número significativo de professores que quer permanecer no magistério. Ela é motivada pela vontade de criar novas situações de ascensão na carreira e de melhorar sua competência pedagógica. Esses professores gostariam de se tornar administradores escolares ou pedagogos e de cursar programas de especialização (nível de pós-graduação).

\section{A lógica da transformação}

Por ser uma profissão dotada de "espírito de corpo" (nos termos descritos por Dubar e Tripier, 1998), o magistério é reconhecido por seu longo passado e pela especificidade das atividades que desenvolve, além de sustentar um caráter quase universal do "ofício" de professor, que foi bem explicitado por Arroyo (1999). Para ele, a importância do magistério se deve ao fato de formar-se ao longo da história, de acompanhar os lentos processos de civilização e de educação no desenvolvimento humano, de acompanhar as tensões sociais, culturais e políticas. O professor dificilmente chega a distanciar-se do ethos, dos estilos, das culturas, das práticas, das identidades, que têm uma longa duração na história. Ainda que situadas em locais tão distantes, no meio de formações sociais e culturais tão diversas, as escolas, 
assim como o perfil dos professores, são quase idênticas.

Mas o magistério é também valorizado por possuir uma natureza própria que o distingue das demais profissões: tratase de uma atividade que deve contribuir para o bem comum. Ele se beneficia, então, do status da profissão, associado à singularidade da função social que deve exercer e a uma certa identidade docente, em que o mito do progresso coletivo confunde-se com o projeto e as ambições individuais.

Segundo Tardif et al. (1998), a identidade do professor oscila entre três modelos:

1) o técnico do ensino define-se por competências de perito no planejamento do ensino; sua atividade repousa em conhecimentos formalizados vindos da pesquisa científica, sua ação situa-se no plano dos meios e das estratégias do ensino; ele busca o desempenho e a eficiência no alcance dos objetivos escolares;

2) o prático reflexivo, reconhecido como profissional de alto nível, capaz de administrar situações em parte indeterminadas, flutuantes, contingentes e de negociar com elas, criando novas e ótimas soluções;

3) o ator social, identificado como agente de mudança, ao mesmo tempo em que é portador de valores emancipadores diante das diversas lógicas de poder que estruturam tanto o espaço social quanto o espaço escolar.

Para esses autores, o último modelo representa a maior parte dos professores brasileiros, assim como aqueles que habitam em regiões onde as riquezas materiais e culturais são extremamente desiguais. O professor ator social questiona as formas dominantes da racionalidade, caracterizadas pelo pensamento instrumental, a ciência formal, as soluções tecnológicas para os problemas sociais, e esforça-se para estabelecer laços com os conhecimentos sociais cotidianos dos mais carentes e integrá-los na formação dos alunos.

Evidentemente, a escolha da carreira docente foi influenciada pelo perfil do ator social, evocado com eloqüência pelos movimentos de democratização da educação desde os anos 80. A maioria dos professores interrogados se vê como "agente de transformação social” e procura orientar-se segundo algumas circunstâncias conjunturais, que combinam valores de natureza intrínseca claramente privilegiados nas lógicas de integração e de profissionalização com valores exógenos relacionados, sobretudo, com o dever comunitário: “eu gostaria de contribuir para a formação da cidadania e participar da educação e da sociedade”, "o professor também é responsável pela mudança da sociedade”, “a construção de uma sociedade democrática depende da escola”.

Concluindo, sublinhamos que a lenta expansão das oportunidades educacionais nos leva a empregar a palavra escolha com prudência, lembrando que o percurso escolar dos professores interrogados se confrontou com obstáculos que frearam a escolarização da população brasileira e restringiram o leque de opções, sobretudo no nível superior. Nessa conjuntura de desafios sucessivos a superar, os programas de formação aparecem como herdeiros de múltiplas sedimentações históricas, hierarquizadas e legitimadas pelo sistema escolar.

A escolha de uma habilitação é sempre uma escolha de vida e representa a antecipação das aspirações profissionais, mas presume-se que essa escolha não existe verdadeiramente quando se vem de uma classe desfavorecida. É importante considerar (a exemplo do que faz Bourdieu, 1964) que a margem de escolha dos jovens dos meios populares é muito limitada. Aqueles que sobrevivem aos mecanismos de seleção e exclusão, típicos de um sistema escolar altamente elitizado onde dificilmente encontram seu lugar, são coagidos a fazer suas escolhas muito cedo e se submetem a processos de socialização que implicam geralmente um verdadeiro desenraizamento: a maioria das professoras interrogadas se confrontou com a transição entre o papel tradicional de mãe e dona-de-casa e o ingresso no mundo do trabalho (mais da metade das suas mães nunca trabalharam fora).

O título escolar, principalmente de nível superior, é dotado de certas garantias institucionais e de valor simbólico, funcionando simultaneamente como passaporte para o ingresso na carreira docente e 
como símbolo de distinção social. Apesar de sofrer profundamente por causa dos baixos salários, o magistério não parece submeter os professores a uma situação de desclassificação social que supostamente lhe estaria inerente, mas, ao contrário, para os interrogados, a obtenção do título representa ascensão cultural, socioprofissional e mesmo econômica.

Observamos, finalmente, que a escolha da carreira docente foi orientada segundo as lógicas de integração, de profissionalização e de transformação, que se concretizam a partir de outras lógicas:

1) uma lógica institucional, veiculada pelas políticas educacionais e pelos programas oficiais de formação inicial e contínua, que visa executar os objetivos educacionais do Estado. Esta lógica coloca em correspondência as aptidões supostas dos jovens estudantes com as necessidades dos setores econômicos (regulados por um sistema complexo de concorrência), procurando ajustar as performances escolares às estruturas a serem preenchidas;

2) uma lógica de proximidade, relacionada com a oferta em termos de habilitações profissionais, que faz com que a escolha seja ponderada pela disponibilidade dos estabelecimentos de ensino da cidade ou da região;

3) uma lógica corporativa, mobilizada pelas associações e sindicatos, que se propõe consolidar a carreira docente e, assim, (re)conquistar direitos considerados fundamentais na construção de uma identidade profissional que lhes permita atuar como agente de transformação social. Essas esferas entendem que a docência se declina em deveres ou em interdições e que, não dispondo realmente das prerrogativas que as leis e regulamentos lhes dizem conferir, os professores têm dificuldades para fazer valer seus direitos.

\section{Referências bibliográficas}

ARROYO M. G. Ciclos de desenvolvimento humano e formação de educadores. Educação e Sociedade, n. 68, p. 143-162, 1999. Especial.

BOURDIEU, P. La distinction. Paris: Minuit, 1979.

. La noblesse d'État: grandes écoles et esprit de corps. Paris: Minuit, 1989.

. Homo academicus. Paris: Minuit, 1998.

. Méditations pascaliennes. Paris: Seuil, 1997.

. La domination masculine. Paris: Seuil, 1998.

BOURDIEU, P.; PASSERON, J.-C. Les héritiers: les étudiants et la culture. Paris: Minuit, 1964.

DUBAR, C. La socialisation. Construction des identités sociales et professionnelles. 2. ed. Paris: Armand Colin, 1998.

. La crise des identités: l'interprétation d'une mutation. Paris: PUF, 2000.

DUBAR, C.; TRIPIER, P. Sociologie des professions. Paris: Armand Colin, 1998.

ELIAS, N. Qu'est-ce que la sociologie? La Tour d'Aigues: L'Aube, 1970.

GOFFMAN, E. La mise en scène de la vie quotidienne. 1. Présentation de soi. Paris: Minuit, 1973. 
HUBERMAN, M. La vie des enseignants. Évolution et bilan d'une profession. Paris: Delachauz et Niestlé, 1989.

HUGHES, E. C. Le regard sociologique: essais choisis. Paris: École des Hautes Études en Sciences Sociales, 1996.

LAPASSADE, G. Grupos, organizações e instituições. 3. ed. Rio de Janeiro: Francisco Alves, 1989.

LAHIRE, B. L'homme pluriel. Les ressorts de l'action. Paris: Nathan, 1998.

POSTIC, M. et al. Motivations pour le choix de la profession d'enseignant. Revue Française de Pédagogie, n. 91, p. 25-36, avril/juin 1990.

TARDIF, M. et al. Formation des maîtres et contextes sociaux, perspectives internationales. Paris: PUF, 1998.

TRIPIER, P. De l'éthique puritaine au "voleur professionnel”: discussion sur la vocation. In: BOURDONCLE, R. et al. Les professions de l'éducation et de la formation. Villeneuve d'Ascq Nord: Septentrion, 1998.

VALLE, I. R. Burocratização da educação: um estudo sobre o Conselho Estadual de Educação do Estado de Santa Catarina. Florianópolis: Ed. da UFSC, 1996.

.Professionalisation et formation des enseignants: la socialisation professionnelle des enseignants de la $1^{\text {re }}$ à la $4^{\mathrm{e}}$ année à Santa Catarina - Brésil”. Paris: Paris V, 2001. (Tese de doutorado).

Da "identidade vocacional” à "identidade profissional”: a constituição de um corpo docente unificado. Perspectiva: Sociologia e Educação. Revista do Centro de Ciências da Educação, v. 20, p. 209-230, jul./dez. 2002. Número Especial.

Ione Ribeiro Valle, doutora em Ciências da Educação pela Faculdade de Ciências Humanas e Sociais da Sorbonne, Universidade René Descartes - Paris V, é professora da Universidade Federal de Santa Catarina (UFSC), Centro de Ciências da Educação (CED), Departamento de Estudos Especializados em Educação (EED).

ionevalle@ced.ufsc.br

Recebido em 20 de abril de 2006.

Aprovado em 17 de agosto de 2006. 